\title{
Travel fatigue and home ground advantage in South African Super 12 rugby teams
}

\author{
M du Preez (BSc (Med) (Hons) Exercise Science) \\ M I Lambert (PhD)
}

Department of Human Biology, Medical Research Council/University of Cape Town Research Unit for Exercise Science and Sports Medicine

\begin{abstract}
Objectives. Studies have shown the existence of a significant home ground advantage in a range of sports. The aim of this study was to determine whether home performances of the South African teams during the 1996 - 2005 seasons were different before touring to Australia and New Zealand, compared with the home matches played after the 4 - 5-week tour. The question was relevant because this competition places unusual demands on the players. For example, the duration of the tournament is 12 weeks, during which time the South African teams travel across $37.3 \pm 2.5$ time zones as they play 11 matches. Therefore, any home ground advantage may be negated by travel fatigue.
\end{abstract}

Outcome measures. The mean points difference was calculated for home fixtures for four South African teams both prior to and following touring during the competitions from 1996 to 2005. Play-off matches were excluded from analysis. Performance was defined as a positive points difference (points difference $=$ points 'for' minus points 'against').

Results. The first finding of the study was that a home ground advantage did indeed exist for all the teams during the tournament (points difference of $6.6 \pm 17.4(N=$ 664 matches) home vs. $-6.8 \pm 17.3$ points away $(N=656$ matches) $(p<0.05)$. There was no difference between the mean 'home' points difference for all the South African rugby teams either before (1.9 points, $N=96$ matches) or after (2.3 points, $N=107$ matches) touring overseas in the Super 12 competition.

\section{CORRESPONDENCE:}

M Lambert

MRC/UCT Exercise Science and Sports Medicine

PO Box 115

Newlands

7725

Fax: 021-686 7530

Tel: 021-650 4569

E-mail: Mike.Lambert@uct.ac.za
Conclusion. The findings suggest that in this tournament unsuccessful campaigns on the part of South African teams could not be attributed to travel fatigue.

\section{Introduction}

In professional sport, much research has focused on the possible advantages ${ }^{1,4,10-12}$ and disadvantages ${ }^{3,17,19,20}$ associated with being the home or visiting team. When tournaments have games played according to a balanced home and away schedule, there is compelling evidence that a home advantage phenomenon exists. ${ }^{6,12}$ Local crowds, familiarity with local conditions, travel and rules appear to contribute to this phenomenon. $^{12}$

The Rugby Union Super 12 competition was an annual sporting event which existed from 1996 to 2005 and involved teams from Australia $(N=3)$, New Zealand $(N=5)$ and South Africa $(N=4)$. The teams competed according to an unbalanced home and away schedule. ${ }^{7,10}$ The South African teams travelled away from home for a continuous 4 - 5 weeks, whereas the Australian and New Zealand teams were away from home for 2 - 3 weeks. The cumulative change in time zones for the South African teams during the competition was about $37.3 \pm 2.5$ time zones compared with 19.7 \pm 1.2 and $21.7 \pm 1.7$ cumulative time zone changes for the Australian and New Zealand teams respectively. Although it has previously been shown that a home ground advantage in this tournament does indeed exist, ${ }^{7,10}$ there is evidence to suggest that the advantages of playing at home may be negated by the disadvantages associated with fatigue resulting from travel and changing time zones. ${ }^{15,16,18}$

In the 10 years of the competition a South African team has never won the tournament. A common explanation among fans and the local media for the relatively poor performances of the South African teams is that they spend more consecutive time away from home than their Australian and New Zealand counterparts and thus accumulate more travel fatigue. At present there are no data to support this perception. This theory can be tested by determining whether the South African teams perform better at home before they travel compared with their home matches after travelling for their 4 5-week trip to Australia and New Zealand. Indeed, if travel fatigue did have a detrimental effect on performance then 
the South African teams would consistently perform worse at home after travelling to Australia and New Zealand compared with their performances at home before travelling. Therefore the aim of this study was to determine whether home performances of the South African teams during the 1996 - 2005 seasons were different before touring to Australia and New Zealand, compared with the home matches played after the 4 - 5-week tour.

\section{Methods}

Scores from 1996 through to 2005, excluding the semi-final and final stages of the Super 12 Rugby Union competition, were obtained for all the teams from Australia $(N=3)$, New Zealand $(N=5)$ and South Africa $(N=4)(N=1320$ matches). The points difference was determined for all the South African teams (Sharks, Stormers, Cats and Bulls) when they played at their home stadiums. A positive points difference indicates that the home team won the match. The matches were categorised into matches played at home before or after travelling on a 4 - 5-week trip to Australia and New Zealand. An analysis of variance (ANOVA) with repeated measures was used to determine differences between teams and home performances either before or after touring (Statistica version 6.0 , Tulsa, USA). Statistical significance was accepted as $p$ $<0.05$. Data are expressed as means \pm standard deviation (SD) or as $95 \%$ confidence intervals (Cls).

\section{Results}

The mean home points difference for all the Super 12 teams ( $N=12)$ in the competition from 1996 to 2005 was positive and significantly greater than the negative mean away points difference $(6.6 \pm 17.4$ points vs. $-6.8 \pm 17.3$ points respectively, $p<0.05$ ). The $95 \% \mathrm{Cls}$ for these values are 5.3 to 7.9 points (home) and -8.1 to -5.4 points (away). These data were calculated from 664 home matches and 656 away matches. The significant difference also occurred when the South African teams were analysed as a subgroup; 0.2 to 4.4 points difference $(95 \% \mathrm{Cl})$ home $(N=221)$ and -14.4 to -9.6 points difference $(95 \% \mathrm{Cl})$ away $(N=219)$.

There was no difference between the mean 'home' points difference for all the South African rugby teams either before (mean $=1.9,95 \% \mathrm{Cl}:-1.4$ to 5.2 points, $N=96$ matches) or after (mean $=2.3,95 \% \mathrm{Cl}:-0.8$ to 5.4 points, $N=107$ matches) touring in the Super 12 competition. The reason that the sample size is reduced when the data were analysed this way is that the teams sometimes did not play home matches either before or after travelling. This depended on the schedule for the season. For example, in 1996 the Cats did not play any home matches before touring and in 1999 the Cats did not play any home matches after touring. Similar examples can also be found for the other teams.

The data are subdivided into the individual teams and shown in Fig. 1. There was no statistical significance between the home points difference before touring and the home points difference after touring for the Sharks $(95 \% \mathrm{Cl}$ of home matches before travelling vs. $95 \% \mathrm{Cl}$ of home matches after travelling: -2.6 to 12.5 vs. -2.5 to 8.8 points), Stormers ( -4.9 to 10.7 vs. -9.9 to 4.1 points), Cats ( -3.1 to 7.4 vs. -3.6 to 11.3 points) and Bulls (-9.7 to 5.1 vs. -1.4 to 10.3 ). However when the data were analysed using magnitude based inferences $^{2}$ it may be concluded that the Stormers had a 'possibly trivial' lower points at home after travelling whereas the Bulls had a 'possibly trivial' lower points difference before travelling (Fig. 1).

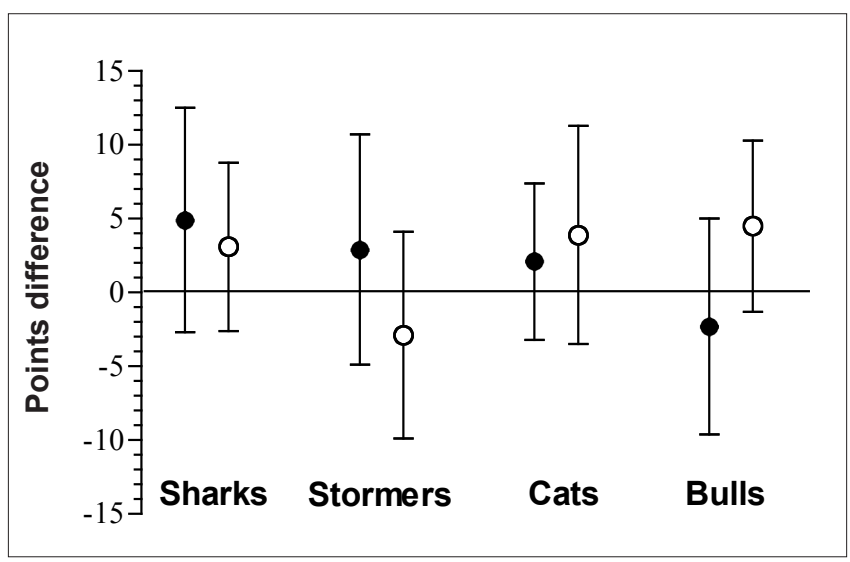

Fig. 1. The points difference for the home matches of the Sharks, Stormers, Cats, and Bulls before departing for (•) and after touring (o) Australia and New Zealand. Values are expressed as means $\pm 95 \% \mathrm{Cl}$. The number of matches analysed are: Sharks $N=24$ before, $N=27$ after; Stormers $N=19$ before, $N=25$ after; Cats $N=29$ before, $\mathbf{N}=25$ after; Bulls $\mathbf{N}=24$ before, $N=30$ after.

\section{Discussion}

The first finding of the study showed that in the Super 12 competition (1996 - 2005), involving 1320 matches, the mean home points difference was positive and significantly greater than the mean away points difference. This home ground advantage also occurred for the four South African teams when they were analysed on their own. This confirms that home ground advantage exists in this competition, supporting findings from du Preez and Walpole ${ }^{7}$ who found a points difference of $7.4 \pm 6.9$ points (home) vs. $-7.4 \pm 7.9$ points (away) in the 2004 competition. Therefore it may be concluded that teams generally outscore their opponents when playing at home in this competition. This may have implications for success in the tournament as the competition lacks balance (i.e. a team either plays 5 or 6 home matches) and a team might play a weaker team at home one year and away the next. ${ }^{10}$

The second finding of this study was that the South African teams did not perform significantly better at home before travelling compared with home performances after returning from their 4 - 5-week trip to Australia and New Zealand. This suggests that reports of South African teams being at a disadvantage because of the travelling were not supported by the data. Had this been the case then the teams would have generally performed at home better before, compared with 
after, travelling. This is in agreement with other studies, $5,13,14$ which found that travel factors like crossing more time zones and having more days off, accounted for less than $1.5 \%$ of the variance in home advantage in baseball and hockey. Courneya and Carron ${ }^{6}$ concluded that effects of travel on the home ground advantage are minimal for professional ranks, and later Gayton and Coombs ${ }^{8}$ showed that the hypothesis applies for amateur sports as well.

The concern and potential problem for Super 12 rugby players is the possible effect of 'jet lag' on their home ground advantage. Pace and Carron ${ }^{13}$ have documented that the severity of 'jet lag' and subsequent recovery is a function of the number of time zones crossed and the direction of travel, with the body readjusting and acclimatising faster for travel in a westbound direction. When returning from Australia and New Zealand South African teams travel in a westbound direction. Thus home ground advantage is less affected by travel than if they had to travel home in an eastbound direction. ${ }^{9}$ The findings of the study therefore suggest that westbound travel after being away for 4 - 5 weeks had no measurable effect on home ground advantage for the South African Super 12 teams.

Based on these findings, playing more rugby matches at home in the Super 12 competition (and the current Super 14 competition) increased a team's chance of doing well in the competition. As there were 12 teams in the tournament, some teams had 6 home and 5 away matches whereas other teams had 5 home and 6 away matches. Therefore, all other factors being equal, the teams with 6 home matches should have had an advantage. An analysis of the data in this study should be interpreted in the context that teams in the Super 12 tournament (and the current Super 14 competition) vary from year to year. Further research is required to explain the perceived problem of the South African teams generally underperforming in this tournament compared with the Australian and New Zealand teams.

\section{Acknowledgements}

The Medical Research Council and the Nellie Atkinson and Harry Crossley Research Funds of the University of Cape Town supported this study.

\section{REFERENCES}

1. Balmer NJ, Nevill AM, Williams M. Home advantage in the Winter Olympics (1908-1998). J Sports Sci 2001; 19: 129-39.

2. Batterham AM, Hopkins WG. Making meaningful inferences about magnitudes. International Journal of Sports Physiology and Performance 2006; 1: $50-7$.

3. Butler JL, Baumeister RF. The trouble with friendly faces: Skilled performance with a supportive audience. J Pers Soc Psychol 1998; 75: 1213-30.

4. Carron AV, Loughhead TM, Bray SR. The home advantage in sport competitions: Courneya and Carron's (1992) conceptual framework a decade later. J Sports Sci 2005; 23: 395-407.

5. Courneya KS, Carron AV. Effects of travel and length of home stand/road trip on the home ground advantage. Journal of Sport and Exercise Psychology 1991; 13: 42-9.

6. Courneya KS, Carron AV. The home advantage in sport competitions: A literature review. Journal of Sport and Exercise Psychology 1992; 14: 2839.

7. du Preez M, Walpole B. Home ground advantage - Fact or fallacy? A comment on the 2004 Super 12 rugby competition. South African Journal of Sports Medicine 2004; 16: 19-21.

8. Gayton WF, Coombs R. The home advantage in high school basketball. Percept Mot Skills 1995; 81: 1344-6.

9. Jehue R, Street $D$, Huizenga R. Effect of time zone and game time changes on team performance: National Football League. Med Sci Sports Exerc 1993; 25: 127-31.

10. Morton HR. Home advantage in southern hemisphere rugby union: $\mathrm{Na}$ tional and international. J Sports Sci 2006; 24: 495 - 9.

11. Nevill AM, Holder RL, Bardsley A, Calvert H, Jones S. Identifying home advantage in international tennis and golf tournaments. J Sports Sci 1997; 15: $437-43$.

12. Nevill AM, Holder RL. Home ground advantage in sport: An overview of studies on the advantage of playing at home. Sports Med 1999; 28: 22136.

13. Pace A, Carron AV. Travel and the National Hockey League. Canadian Journal of Sports Sciences 1992; 17: 60-4.

14. Pollard R. Home advantage in soccer: A retrospective analysis. J Sports Sci 1986; 4: 237-48.

15. Recht LD, Lew RA, Schwartz WJ. Baseball teams beaten by jet lag. Nature 1995; 377: 583.

16. Snyder EE, Purdy DA. The home advantage in collegiate basketball. Sociology of Sport Journal 1985; 2: 352-6.

17. Wallace HM, Baumeister RF, Vohs KD. Audience support and choking under pressure: A home disadvantage? J Sports Sci 2005; 23: 429-38.

18. Waterhouse J, Reilly T, Edwards B. The stress of travel. J Sports Sci 2004; 22: $946-66$

19. Wright EF, Jackson W. The home-course disadvantage in golf championships: Further evidence for the undermining effect of supportive audiences on performance under pressure. Journal of Sport Behavior 1991; 14: 5160.

20. Wright EF, Voyer D. Supporting audiences and performance under pressure: The home-ice disadvantage in hockey championships. Journal of Sport Behavior 1995; 18: 21-8. 